\title{
A possible pitfall in the identification of Pasteurella spp. with the API system
}

\author{
J. M. T. HAMILTON-MILLER \\ Department of Medical Microbiology, Royal Free Hospital School of Medicine, Pond Street, London NW3 206
}

A recent case report of in-utero infection with Pasteurella multocida ${ }^{1}$ stimulated a plea $^{2}$ for a more detailed description of the causal organism. In reply, the original authors ${ }^{3}$ described the isolate as follows: growing on blood agar as small, gray, shining colonies, but not on MacConkey Agar; gramnegative cocco-bacilli; indole produced, catalase and oxidase present; nitrate reduced ; urease absent; glucose and sucrose "characteristic of P. multocida" (presumably fermented); sorbitol fermented.

The strain had been identified with the API system.

This description is strikingly similar to that which could be applied to some Haemophilus spp., especially certain biotypes of $H$. influenzae and $H$. parainfluenzae. ${ }^{4}$ The main discrepancy is in the growth on blood agar. However, many Haemophilus spp. will grow sufficiently on most blood-agar formulations for growth to be discernible. This is of considerable relevance, as it may not be widely appreciated that if Haemophilus spp. are unwittingly put into the API system, they can be misidentified as Pasteurella spp. We first became aware of this when a urinary isolate of $H$. influenzae was misidentified as $P$. multocida. ${ }^{5}$ Because of these possibilities, a further three strains each of $H$. influenzae and $H$. parainfluenzae (identified by their requirements for $\mathrm{X}$ and $\mathrm{V}$ factors) were tested in this laboratory in API 20E and 20NE identification strips (bioMérieux UK Ltd, Basingstoke, Hants). The results, together with those from the previous strain reported, ${ }^{5}$ are shown in the table. These indicate that there is a serious possibility that $H$. influenzae or $H$. parainfluenzae may be misidentified as Pasteurella spp. (most likely as $P$. pneumotropica).

In view of this, it would be reasonable to recommend that if an isolate is identified with the API system as $P$. pneumotropica, $P$. multocida or $P$. haemolytica, especially if it comes from an unexpected source (e.g., without any history of animal contact), the strain should be tested for X and V dependency. Pasteurella spp. should grow well on the nutrient agar used for this test, whereas Haemophilus spp. grow only around the appropriate supplements.

I am grateful to Mrs Saroj Shah for her assistance.

Table. "Identification" of $H$. influenzae and $H$. parainfluenzae by the API system

\begin{tabular}{|c|c|c|}
\hline \multirow{2}{*}{ Species and strain no. } & \multicolumn{2}{|c|}{ API code and identification } \\
\hline & $20 \mathrm{E}$ & $20 \mathrm{NE}$ \\
\hline $\begin{array}{l}\text { H. influenzae } \mathrm{JI}^{*} \\
\text { H. influenzae } \mathrm{JI}^{*} \\
\text { H. influenzae } \mathrm{A} 1 \\
\text { H. influenzae } \mathrm{A} 2 \\
\text { H. influenzae } 13179 \\
\text { H. parainfluenzae } 12938\end{array}$ & $\begin{array}{l}1054004 \\
\text { Pasteurella spp. } 97 \% \\
0050004 \\
\text { does not compute } \\
0050004 \\
\text { does not compute } \\
0050004 \\
\text { does not compute } \\
0140004 \\
\text { P. multocida } 57 \cdot 8 \% \\
1000004 \\
\text { Pseudomonas paucimobilis } 42 \cdot 9 \% \\
\text { or } \\
\text { Pasteurella } \text { spp. } 37 \cdot 4 \% \\
1110004 \\
\text { Pasteurella } \text { spp. } 97 \cdot 2 \% \\
0150004 \\
\text { does not compute }\end{array}$ & $\begin{array}{l}3200004 \\
\text { P. pneumotropica } 98 \cdot 1 \% \\
7200004 \\
\text { P. pneumotropica } 99 \cdot 8 \% \\
3200004 \\
\text { P. pneumotropica } 98 \cdot 1 \% \\
3200004 \\
\text { P. pneumotropica } 98 \cdot 1 \% \\
3000004 \\
\text { P. multocida } 93 \cdot 1 \% \\
1020004 \\
\text { P. haemolytica } 93 \cdot 8 \%\end{array}$ \\
\hline
\end{tabular}

*Two strains isolated consecutively from the same patient. ${ }^{5}$ 


\section{References}

1. Waldor M, Roberts D, Kazanjian P. In utero infection due to Pasteurella multocida in the first trimester of pregnancy: case report and review. Clin Infect Dis 1992; 14: 497-500.

2. Weaver RE. In utero infection due to Pasteurella multocida. Clin Infect Dis 1992; 15: 881-882.

3. Kazanjian PH, Waldor M. Reply. Clin Infect Dis 1992; 15: 882.
4. Kilian M, Haemophilus. In: Balows A, Hausler WJ, Herrmann KL, Isenberg HD, Shadomy HJ (eds) Manual of clinical microbiology, 5th edn. Washington, D.C., American Society for Microbiology. 1991: 463-470.

5. Morgan MG, Hamilton-Miller JMT. Haemophilus influenzae and $H$. parainfluenzae as urinary pathogens. $J$ Infect 1990 ; 20: $143-145$.

J. Med. Microbiol. - Vol. 39 (1993), 79

(c) 1993 The Pathological Society of Great Britain and Ireland

\section{ANNOUNCEMENTS}

\section{The Society for Anaerobic Microbiology}

VIII International Symposium will be held at Churchill College, Cambridge on 22nd-24th July, 1993

\section{Provisional programme}

Thursday, 22 July p.m. Gram-positive anaerobes in periodontal disease (joint meeting in conjunction with the Oral Microbiology and Immunology Group). Chairman: W. Wade (Cardiff); Speakers: J. Greenman (Bristol), U. Gobel (Freiburg)

Friday, 23 July a.m. Anaerobic intestinal ecosystems. Chairman: M. Hudson (CAMR, PHLS); Speaker: C. Stewart (Aberdeen)

Ecology and epidemiology of $C$. difficile. Chairman and keynote speaker: S. P. Borriello (Nottingham); Speakers: T. V. Riley (Perth), B. D. Cookson (CPHL)

p.m. Broad-spectrum antibiotics and anaerobes. Chairman and keynote speaker: E. Goldstein (Los Angeles); Speakers: T. J. M. van Steenbergen (Amsterdam), G. Reysset (Paris)

Saturday, 24 July a.m. DNA technology and anaerobes. Chairman: B. Wren (London); Speakers: C. von Eichel-Streiber (Mainz), S. Cole (Paris)

The Symposium will include free oral presentations and posters and the Proceedings will be published.

Further information may be obtained from:

Dr J. Brazier, Anaerobe Reference Unit,

Department of Medical Microbiology and Public Health Laboratory,

University Hospital of Wales, Heath Park,

Cardiff CF4 4XN

Tel. Cardiff (0222) 742171

Fax. (0222) 751729

The Society for Anaerobic Microbiology is grateful to the Federation of European Microbiological Societies (FEMS) for sponsoring the attendance of young European scientists at this meeting by funding a series of bursaries. Young research workers in any field of anaerobic microbiology who wish to apply for financial assistance to attend the Symposium should apply to the SAM at the above address.

\section{OAKLEY LECTURESHIP}

The CL Oakley lecturer will be nominated by the Microbiology Section of the Pathological Society to speak at the winter meeting of the Society in January 1994. Any member wishing to put forward the name of a possible recipient of this lectureship should submit this in writing to Dr Rosamund Williams at the Pathological Society, 2 Carlton House Terrace, London SW1Y 5AF. 